\title{
IVNO CAELESTIS en la colonia hispanorromana de ILICI
}

\author{
antonio M. Poveda Navarro *
}

\section{RESUMEN}

En las últimas décadas se han desarrollado numerosas investigaciones sobre la religión ibérica, incidiendo sobre las divinidades indígenas del tipo Diosa Madre y especialmente en su posible presencia a través de la indudable existencia de una importante diosa de los animales, una Potnia Theron que la mayoria de las veces se manifiesta como Hippon, cuyo culto parece documentarse con claridad en el territorio ibérico del sureste peninsular conocido en la antigüedad como Contestania. Sus características de divinidad de la naturaleza, de la fecundidad, de la vida y de la muerte y de los animales, le permitió ser asociada y sincretizada con la griega Artemis y la púnica Tanit.

La gran influencia que ejerció el mundo púnico del norte de África y sobre todo de lbiza sobre esa región ibérica, provocó la fusión y confusión de la Potnia local con aquella deidad púnica difundida desde esas áreas. Esto explicaría que al producirse la denominada romanización de ambas zonas, conocieran por igual la interpretatio de Tanit como Ivno Dea Caelestis. El caso que mejor ilustra este proceso se ha verificado arqueológica y epigráficamente en la colonia romana de llici Augusta (Elche).

Dentro del arte ibérico se han querido reconocer varias representaciones iconográficas de la Gran Diosa Madre, en unos casos son terracotas en las que aparece como curótrofa o nutricia y en otros es una dama sedente ilustrada sobre cerámicas donde aparece dibujada, ambas versiones datan en general de los siglos III al I a.C.. También son muy famosas en la

* Museo Arqueológico de Elda. 
clase de las sedentes un grupo de esculturas del siglo IV a.C., son las representaciones que el ibero realizaba como su Gran Señora o Gran Dama, de las que las Damas de Baza, Cerro de Los Santos, Guardamar o Elche (llici) pueden ser algunas de sus principales imágenes (R. RAMOs, 1995b, p. 107). También en llici (Alcudia de Elche) se ha creído identificar las versiones de la deidad como Potnia Theron, destacando su matiz de Hippon o señora de los caballos, animales tan abundantemente representados sobre la cerámica ibérica pintada (A. Ramos, 1990) de esta ciudad de la Contestania. Precisamente una vasija de esa variedad cerámica presenta una divinidad alada entre dos équidos alados y rampantes que como si fuesen una biga sagrada parecen ayudarle a ascender desde la tierra (J.Mํ. BLÁZQUEZ, 1956, pp. 747-748, fig. 3; 1977, pp. 305-306, fig. 107. S. Nordström, 1973, pp. 210 211, fig. 51,1. E.Mª Maestro, 1989, pp. 231-232, fig. 79. R. Ramos, 1991, p. 36, lám. V).

Esta Potnia Hippon alada se relaciona estrechamente con los abundantes exvotos de figuritas, grabados y relieves de équidos recuperados en varios santuarios ibéricos de la Alta Andalucía y el Sureste (ANTONIO M. PovedA, 1995, pp. 155-156, nota 10), que demuestran la existencia de un culto protector de los caballos y de la fecundidad simbolizado por la Potnia Hippon y su paredro el Potnios Hippon.

Estamos ante una divinidad indígena local, que cuando aparece sobre la cerámica de llici está caracterizada morfológicamente por su iconografía acampanada, portar alas, aparecer con signos vegetales y rodearse de animales, destacando entre ellos la presencia de serpientes (ANA Ma VÁzQUEZ, en prensa). Puede representarse de cuerpo entero, de busto o tan solo con la cabeza. Este grupo de deidades aladas son el motivo principal en la cerámica de Elche (M. MENÉNDEZ, 1988), que ha sido interpretado como plasmación del surgimiento de la vida, se asocia a la representación de una divinidad femenina cuyo rostro aparece brotando de la tierra (R. Ramos, 1995b, p. 107), de modo que tendría un significado de rito de tránsito de la tierra a la superficie, de la noche al día, siendo un claro ejemplo de que se trata de una diosa ctonia.

Todas estas representaciones se fechan entre el siglo II y el I a.C. y tienen su origen en un primer prototipo escultórico aparecido en el parque infantil de tráfico de Elche, datado entre el siglo $V$ y el IV a.C. (R. RAmos, 1988, p. 368. Ma.C. MARín, 1987, p. 66). Se trata de un grupo escultórico compuesto por una esfinge que era montada por la figura del difunto que es transportado por ella, que entre sus garras delanteras contiene una figura femenina acampanada y de alas plegadas, que parece representar a una divinidad con un clarísimo paralelo en algunas terracotas púnicas de Cartago 
y de Ibiza ( P. Cintas, 1976, p. 368. M르. Aubet, 1982, lám. XIl, tipo 12, lám. XIII, tipos 15 y 16, lám. XIV, tipos 17-19) identificadas con la diosa púnica Tanit, que con igual iconografia se ha representado sobre la cubierta de un sarcófago también de Cartago (G. CharLes Picard, 1954, pp. 66 ss.).

De modo que delante de la esfinge ilicitana tendriamos igualmente a Tanit, confirmándose la existencia de su culto en Elche y sus poderes funerarios y psicopompos (Ma.C. MARín, 1987, p. 66). Esta morfología de la diosa es la misma que la de las figuras aladas de la cerámica citada del mismo lugar, sobre todo de las piezas de cuerpo entero y acampanado ( $R$. Ramos, 1991, pp. 36-38, lám. VII y VIII).

Creemos que la aparición de la iconografía de Tanit con sus típicas formas púnicas (de Cartago e Ibiza) en Elche obedece a la existencia de una deidad local, posible Diosa Madre con manifestaciones de Potnia, que por la fuerte influencia cultural cartaginesa ha recibido un préstamo iconográfico de aquella. Ideológicamente también pudo haber una asimilación pues estamos ante una divinidad ibérica de la fertilidad, de la fecundidad, de la vida natural y salvaje, especialmente de los caballos y en un ambiente de fuerte presencia de la serpiente, todo ello es común a las características de Tanit y de su equivalente en el ámbito griego Artemis.

Parece pues claro que se pudo dar un sincretismo de la Potnia venerada en Contestania con la citada Tanit, en el que la interpretatio sería más bien del ibero que no del púnico.

Esta Tanit iberizada fue una deidad imperante en llici desde al menos el siglo IV a.C. hasta el siglo I a.C., convirtiéndose en su diosa poliada o patrona de la urbe, circunstancia que se verá continuada con la romanización de la ciudad, de modo que cuando en la ahora colonia latina denominada lulia llici Augusta, se erija un templo romano en la zona del foro, hacia los años 13-12 a.C., la divinidad a quien se le dedica no será otra que Ivno, tal y como nos ilustra una emisión de semises (VIVES, 1926, lám. CXXXIII, 4-5. Må. DEL MAR Llorens, 1987, pp. 108-117, láms. VI-IX. A. BELTRÁN, 1994, 48-50) de esta urbe.

En esas monedas aparece en el anverso la cabeza laureada de Augusto mirando hacia la derecha, mientras en el reverso presentan un templo tetrástilo cuyo friso del arquitrabe contiene la inscripción IVNONI, además en los intercolumnios y a sus flancos aparecen las siglas $C \cdot 1 \bullet I L \bullet A$, toda esta iconografía y leyendas están circundadas por los nombres de los duoviri quinquennales Q. Papirivs Carvs y Q. Terentivs Montanvs. Tales piezas numismáticas se habrian acuñado hacia los años 13-12 a.C.

La aparición de la dedicatoria en dativo a Ivno está incidiendo en la construcción o consagración de un templo en la ciudad expresada por 

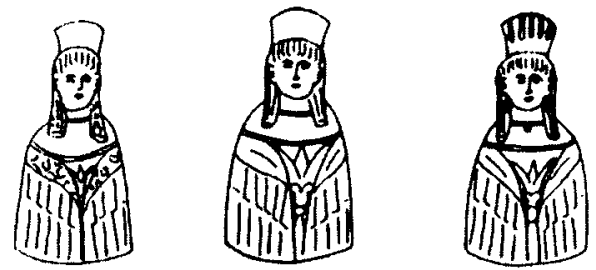

1
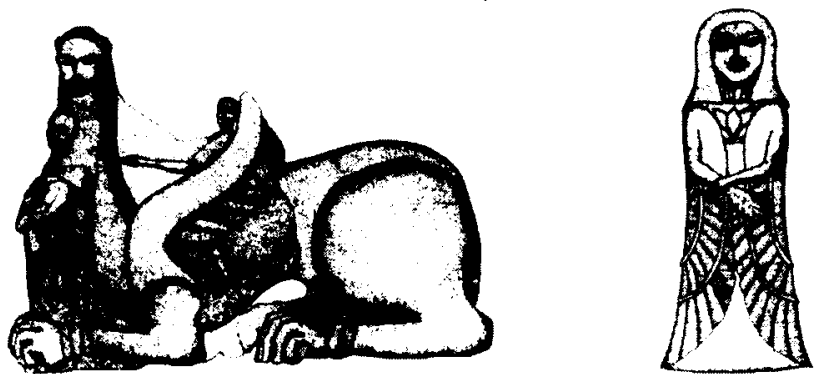

2

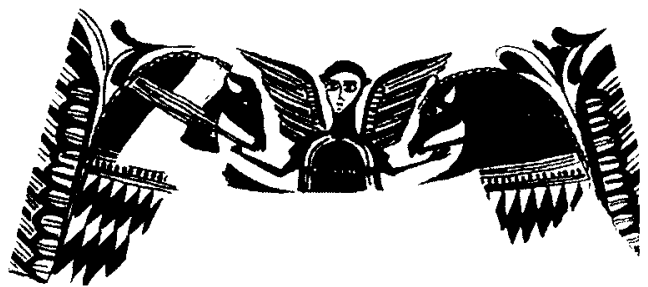

3

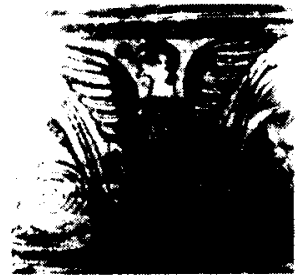

4

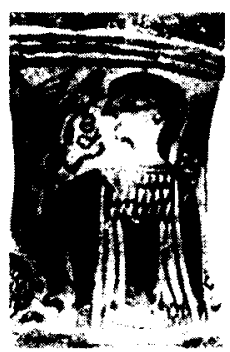

5

Figura 1. Representaciones iconográficas de Tanit en Ibiza y Elche.

1. Tanit de Ibiza (terracotas). 2. Tanit de Elche (escultura). 3. Potnia de Elche (pintura vascular). 4. Tanit de Elche (pintura vascular). 5. Tanit de Elche (pintura vascular). 
aquellas siglas, que son las de la colonia lulia llici Augusta, donde evidentemente existiria un importante culto local a esa divinidad, o con seguridad a la deidad indígena local más importante que además, por sus características era fácil asociarla a aquella diosa romana. Como hemos visto antes esa dea estaba constituida por el sincretismo entre una Gran Señora local del tipo Potnia y la púnica Tanit, ambas conocidas en la cultura feniciopúnica e ibérica como protectoras de los caballos. Como quiera que también Ivno era la patrona de la caballeria de los romanos (A.BeltRán, 1994, pp. 54 y 57) y lo que es más importante, era la interpretatio que estos hacian de la Tanit de Cartago, capital púnica arrasada por Roma en el año 146 a.C. que tenía como divinidad suprema a aqueIla, cuando en el año 122 a.C. C. Sempronivs Gracchus funde sobre las cenizas del lugar una colonia romana la denominará Colonia Ivnonia. Además se reconstruyó el templo sede de la diosa para que su estatua fuera repuesta (G.H. Halsberghe, 1984, pp. 2204 y 2208-2210). Pero ahora los romanos la denominaron Ivno Caelestis o simplemente Dea Caelestis (Plutarco, Vita C. Gracchi, ed. B. Latzarus, 1951-1955).

La identificación de la Dea Caelestis con Ivno por parte de Roma data de la fase republicana ${ }^{1}$, de modo que cuando en la colonia de llici, en época de Augusto (años 13-12 a.C.), se erige un templo que perpetúe el culto a la Tanit iberizada local, ahora llamada Ivno, ésta ya era denominada y conocida por los romanos como Caelestis. Estamos pues ante un proceso religioso de sincretismo y cambio de nombres entre divinidades semejantes, idéntico al acaecido en Cartago y el mundo bereber-púnico del norte de África al producirse la romanización (M. LE GLAY, 1975, p. 139; 1984, p. 56).

Desde la fundación de Cartago por los fenicios sus habitantes adoraron a Tanit como domina y protectora de sus lugares sagrados, cuando posteriormente con la romanización la diosa fue rebautizada con el nombre de Caelestis, conservó e incluso acrecentó su posición excepcional, por ello recibió sobrenombres y calificativos del tipo Augusta, Sancta, Magna, Virgo, Aeterna y con bastante frecuencia Domina (M. LE GLAY, 1984 , p. 55, notas 34 y 36 . G.H. HALSBERGHE, 1984, pp. 2203-2205, notas 8 y 15), como por ejemplo se observa en una inscripción en el zócalo de una estatua dedicada a Dominae Caelesti (CIL VIII 226589). Ese apelativo es fundamental para reafirmar la importancia del culto a Ivno Dea Caelestis en llici, confirmando la antigua idea de que esta diosa era pro-

CIL VIII, 1424: IVnoni Caelesti Augustae sacrum Modia Victoria cum suis votvm solvit libens animo; A. MERlin, Inscriptions latines de la Tunisie, París 1944, p. 125, $\mathrm{n}^{\circ} 708$ : Ivnoni Caelesti Augustae sacrum pro salute ...; CIL. VIII, 25994: Ivnoni Caelesti sacrvm. 

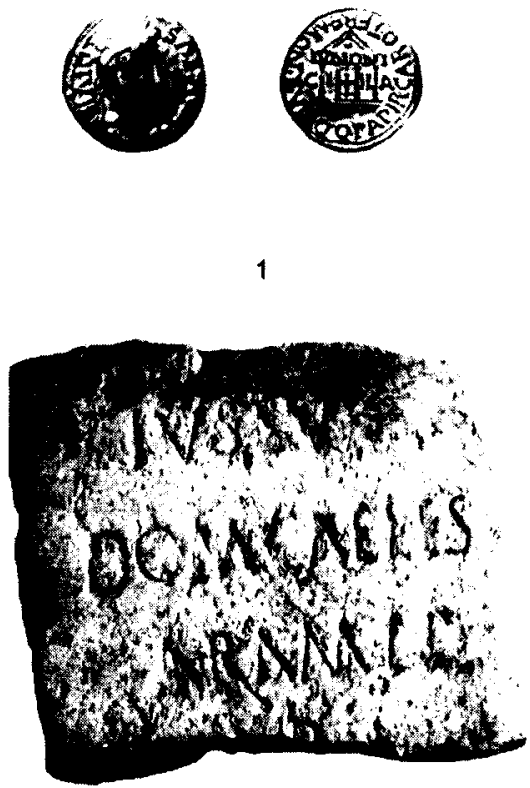

2

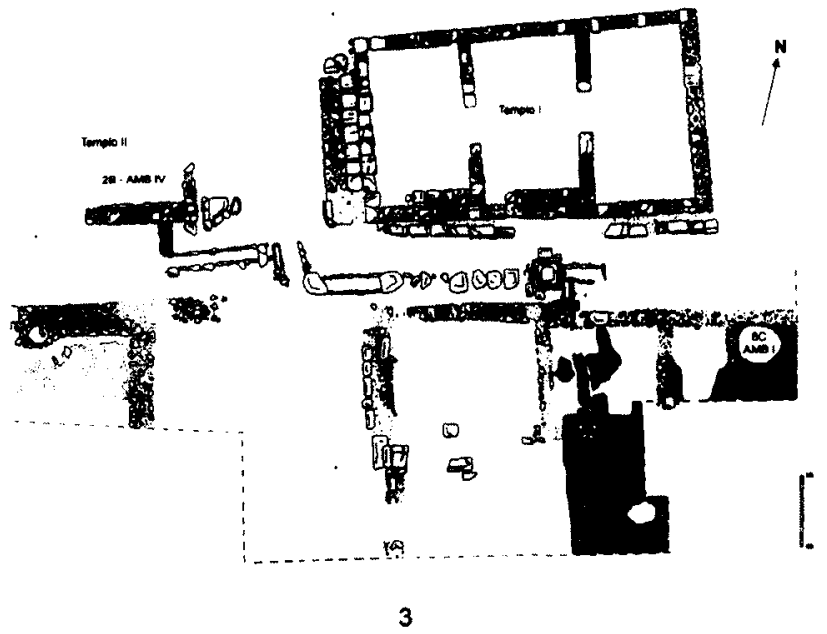

Figura 2. Evidencia numismática, epigráfica y arqueológica de la existencia del culto a Ivno Dea Caelestis en Ilici.

1. Semis de Augusto (12 - 10 a.C.) acuñado en llici. 2. Inscripción a Dea Caelestis sobre Ara. 3. Area del Foro de lici con estructuras conservadas de los templos de época de Augusto. 
bablemente la heredera de Tanit en dicha urbe (G. Charles PICARD, 1954, pp. 101-108).

Este planteamiento cobra ahora fuerza por la reciente identificación de una inscripción (J. CoRELl et alii, 1993, $n^{\circ} 190$, fot. 190. A. BeltRÁN, 1994, p. 57. R. RAMOS, 1994 , p. 50; 1995a, p. 350) recogida antaño en la Alcudia de Elche, solar de la antigua llici. Se trata del fragmento de una ara realizada sobre piedra caliza, rota por los extremos superior e inferior, de modo que se conserva con una altura de $30 \mathrm{~cm}$ y $31 \times 29 \mathrm{~cm}$. de dimensiones. Las letras de la inscripción oscilan en su altura entre 3 y $3{ }^{\prime} 5 \mathrm{~cm}$. y han sido trazadas en capital cuadrada de buena factura, con cierta tendencia a inclinarse hacia la izquierda. La letra A presenta el trazo transversal colgado del asta derecha mientras la letra $P$ tiene el círculo totalmente abierto. En la parte superior que falta de la piedra estaría el nombre del dedicante.

El tipo de letra empleado y su soporte permiten datarla entre el final del siglo I a.C. y los comienzos del I d.C.(J. Corell et alii, 1993, $n^{\circ} 190$ ).

La pieza pertenece a los fondos antiguos del Museo Arqueológico Municipal de Elche, donde se conserva procedente de la colección de don Pedro Ibarra, que excavó en la Alcudia de Elche a partir del año 1890.

\section{TEXTO:}

iussu

Dom(inae) Caeles(tis)

aram /(ibens) $p$ (osuit)

Traducción: ..., por orden de la Señora Celeste, ha erigido esta ara de buen grado.

No cabe absolutamente ninguna duda de que la diosa a la que aquí se hace referencia es la Tanit "iberopúnica", que al romanizarse ahora se transforma en Ivno la Dea Caelestis, tal y como hemos explicado anteriormente. De modo que esta mención de la Dominae Caelestis hace referencia directa a la Ivno mencionada en el arquitrabe del templo de las monedas citadas de llici, pues como advirtiera A. García y Bellido (1957, p. 11) el nombre que podemos considerar como oficial es el de Ivno Caelestis, aunque con el paso del tiempo se simplificó en Caelestis.

Precisamente en los últimos años se ha verificado la existencia de su culto en el santuario ibérico suburbano de Torreparedones, donde fue hallado un exvoto escultórico de piedra, representado por una figura femenina que tiene en su frente la inscripción latina Dea Caele<s stis (J.A.

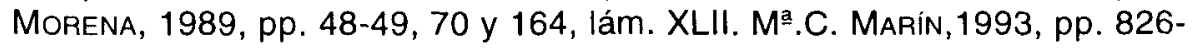


$827, n^{\circ} 1$, lám. 1 y $2 ; 1994$, pp. 217-225, lám. 1), de modo que el nombre está en nominativo y por tanto hemos de interpretar que estamos ante el exvoto representativo de la propia diosa. La datación de la escultura o al menos de la leyenda, se lleva al siglo I a. C. (Ma C. MARín, 1993, p. 826; 1994 , p. 221) aunque analizando la paleografia F. Coarelli propone una fecha de pleno siglo II d.C. ${ }^{2}$.

Opinamos que se trata de un santuario indígena en un área de profunda aculturación púnica, de modo que el oferente o depositante del exvoto divino ha podido ser un turdetano influido culturalmente por un fuerte contacto con el mundo púnico andaluz, incluso un mestizo de ambas culturas puede estar detras de esta acción piadosa. Tales opciones parecen más sencillas y posibles que una inicial propuesta, que plantea que el actor del deposito fuese una persona de origen púnico (Ma.C. MARiN, 1993, p. 827; 1994, p. 225), hecho que no es del todo descartable aunque el ejemplo presentado aquí de llici (Alcudia de Elche) nos inclina hacia nuestra primera opción.

En los cultos indígenas era muy corriente la consulta directa e indirecta a la divinidad quien solía contestar por medio de oráculos y sueños.

Este es el caso de Caelestis que tenía oráculo en su templo principal, en Cartago. Por ello no es extraño que algunas inscripciones de esta diosa fueran mandadas por la misma mediante una incubatio, precepto o consejo onírico enviado desde el santuario al propio dedicante (A. GARCía y BELLIDO, 1957, p. 20). Precisamente este parece ser nuestro caso ya que el uso del término iussu tiene ese significado de mandato divino, que procedería del mismo lugar donde se halló la inscripción pues es obvia la existencia de un templo sede de la diosa en este sitio, como nos ilustra el templo del semis acuñado en esta ciudad probando que allí se le erigió.

Por otra parte y verificando la presencia de ese lugar sagrado la arqueología de llici nos ha revelado un importante conjunto de elementos arquitectónicos (R. RAmOS, 1975, pp. 164-165, lám. LXXX; 1995a, p. 350), que deben pertenecer a un edificio sacro de la segunda mitad del siglo I a. C. Se trata de dos basas molduradas de estilo ático, fustes de tipo disminuido con terminación de astrágalo, dos capiteles completos y fragmentos de otro de morfología jónica que ofrecen el cimacio decorado con temas aovados y apuntados, sobre los que descansa una almohadilla que termina en las volutas, tres fragmentos de un tipo de cornisa formada por un

2 El profesor Coarelli expresó tal opinión en el transcurso del III Congreso Histórico Arqueológico Hispano-Italiano, cuyas actas están en prensa y que se celebró en Toledo, en el año 1993. 
cuerpo liso, una zona de mútulos sobre la que se extiende una faja de dentellones rectangulares, un segundo cuerpo liso más prominente y la cima o goterón de sección curva.

El templo que aparece en las monedas emitidas con Augusto es tetrástilo, con podium de tres gradas cuyos extremos disminuyen de tamaño para adaptarse a la curvatura de la leyenda. Algunos ejemplares presentan sus basas de tipo ático, los fustes de las columnas presentan a veces un engrosamiento central, y los capiteles tienen secciones trapezoidales 0 rectangulares. El entablamento presenta las vertientes realizadas a doble línea, seguramente para indicar cornisas o molduras. En el intercolumnio central la puerta está dibujada por una línea vertical indicando la unión de las dos hojas y una o tres rayas horizontales marcan los casetones. Esta arquitectura ilustrada por la numismática de llici es próxima a la documentada arqueológicamente en el lugar, de modo que quizá sean pertenecientes a una misma construcción templaria ( ${ }^{a}$. DEL MAR LLORENS, 1987, pp. 21-22). Sin embargo, para algún investigador no existe la menor seguridad de que los numerosos restos arquitéctonicos hallados en la Alcudia que acabamos de describir, correspondientes a uno o más edificios religiosos, pertenezcan al templo de las monedas, aunque no descarta que esto fuera posible (A. Beltrán, 1994, p. 52).

Recientemente las excavaciones realizadas en el yacimiento han aportado nuevos datos sobre la existencia de templos romanos en llici. En primer lugar se localizó una construcción (R. RAmOS, 1995a, pp. 349-350) de planta rectangular, orientada de oeste a este, que se eleva sobre el nivel de pavimento mediante un plinto. Los muros son de opus africanum, de técnica de telar, con alternancia de sillería y mampostería revocada con enlucido de cal.

El edificio se distribuye en dos estancias, pronaos y cella, que aparecen separadas por una puerta central con jambas de silleria almohadillada.

Su pronaos se fabricó mediante la prolongación de antas presentando una morfología de templo con dos columnas entre aquellas y con los extremos, continuación unitaria de los muros de la cella, en forma de pilastras, de modo que se trata de un templo díptilo in antis. Su acceso está formado por una grada de sillería y un enlosado inferior que enlaza con el nivel de pavimento exterior.

La construcción dispone de $6 \times 11,50 \mathrm{~m}$. de superficie, encontrándose elevada $0,63 \mathrm{~m}$. sobre el nivel de pavimento. Su excavador la data en el último cuarto del siglo I a. C.

Durante las labores arqueológicas de su exhumación se recuperó un fragmento de cornisa similar a los ya localizados en ese sector del yacimiento y que hemos descrito más arriba. 
En la campaña de excavaciones arqueológicas desarrollada en el verano del año 1994, se descubrieron restos de una estructura arquitectónica (J. Molina y A.M. Poveda, en prensa) semejante al edificio descrito y ubicada frente al mismo. Solamente se conservan los muros y cimentación del ángulo sureste. Esta nueva construcción presenta como la anterior la técnica muraria del opus africanum, igual orientación, graderío de acceso y refuerzo de grandes sillares en el ángulo exterior.

Las cerámicas halladas en el estrato de tierra sobre el que se recortó la fosa de fundación datan este nuevo edificio hacia la última década del siglo I a. C., en época de Augusto.

Las características constructivas, de orientación, alineación y ubicación de estos restos arquitectónicos hablan en favor de considerarlos pertenecientes a un segundo templo romano claramente relacionado con el anteriormente descrito. De modo que cualquiera de los dos edificios de culto puede ser asociado al ilustrado en los semises de llici como perteneciente a Ivno. No obstante se debe ser cauto ya que nuevos descubrimientos templarios podrían variar y aclarar esa adscripción.

De la lista de templos in antis de la península Ibérica (G. BURGHOLzER, 1994, pp.78-79), cercana a la veintena, A. Beltrán (1994, p. 54) ve en uno de Azaila un claro paralelo para el de llici, ya que incluso en aquel caso el edificio sacro estaba dedicado al culto de Ivno, pues en su interior se encontró una cabeza de bronce identificada con esta diosa. También, entre este tipo de templos se han encontrado otros paralelos para el de la Alcudia de Elche, destacando el designado como $C$ de Belo por haberse localizado en él una estatua sedente de Ivno (R. Ramos, 1995a, p. 349).

El culto a Ivno identificada como Caelestis al desarrollarse en ambientes ibéricos de influencia púnica, está igualmente documentado en otros sitios de Contestania cercanos a llici, es el caso de Lucentum, en el yacimiento del Tossal de Manises y la Albufereta de Alicante.

Poco después del año 1701 fue hallada una inscripción (Anonymus Montfauconii, f.13, 10. CIL II 3557 = ILER 2072. D. Tafalla, 1972, p. 67. L. Abad, 1984 , p. 92, $n^{\circ}$ 3. M.A. Rabanal, 1985, p. 381. M.A. Rabanal y J.M. Abascal, 1985, pp. 194-195, $n^{\circ} 4$. L.A. Curchin, 1990, $n^{\circ}$ 787-788. L. Abad y J.M. Abascal, 1991, p. 101.) en la esquina de una casa de una finca rural, cerca de la Albufereta. Actualmente es imposible fijar la fecha exacta del descubrimiento y el lugar del mismo. Al parecer la piedra utilizada como soporte fue la caliza local denominada de San Julián y sus dimensiones eran de "cerca de dos palmos de largo y algo más de palmo y quarto de ancho". Hoy está en paradero desconocido. La estructura y el formulario de la inscripción permite datarla en época imperial, en el siglo II d.C. 
TEXTO:

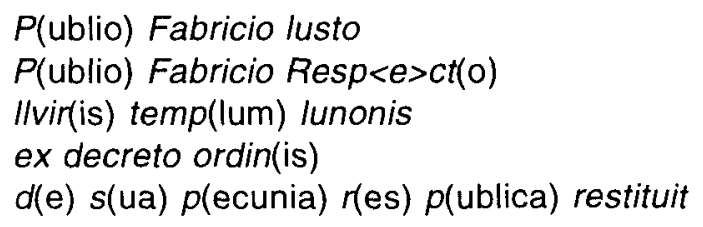

Traducción: Siendo duunviros Publius Fabricius lustus y Publius Fabricius Respectus, la ciudad restauró con fondos públicos el templo de Ivno por decreto de los decuriones.

Gracias a esta inscripción conocemos algunos de los duunviros ordinarios del municipio latino de Lucentum, que al figurar sus nombres en ablativo fecharían el año de la restauración del templo, pero sobre todo nos permite disponer de una prueba fehaciente de que el culto ibero-púnico que Tanit recibía en la zona, perduró sincretizado con Ivno Caelestis en el momento de la romanización.

Esta lápida pertenecía a un monumento conmemorativo de la restauración que en el siglo II d.C., se realizó en un templo dedicado a Ivno que debió erigirse en la primera mitad del siglo I d.C. (L. ABAD Y J.M. ABASCAL, 1991, p. 101).

Para finalizar, hay que hacer notar que no hemos de olvidar que el proceso de sincretismo y de interpretatio de TANIT-IVNO-DEA CAELESTIS en el sur de la península lbérica, desde el ámbito ibero-púnico al romano, es idéntico al producido en el norte de Africa, donde Le Glay lo reconoció bien (M. LE GLAY, 1975, p; 1984, p. 56), en este caso desde la esfera de lo bereber púnico a lo romano. Hay que recordar además la relación políticocultural y económica (E. GonZÁlez, 1983, pp. 13-26) de ambas áreas cuando se producen estos fenómenos, pues dos monarcas norteafricanos de la proto Mauritania Caesarensis, luba II y su hijo Ptolomeo, eran magistrados patronos de Gadir y Carthago Nova, principales urbes púnicas de Hispania. Y además, llici tenía como ciuitas contributa a Icosium, núcleo ubicado bajo la actual Argel, en la costa africana frente a Elche, a tan solo $320 \mathrm{~km}$. de distancia, es decir a un día y medio de travesía marítima. Esto no presupone presencia étnica afro-púnica pero si posibles acciones comerciales y conmemorativas, religiosas, de interes político-cultural donde ciertos cultos son instrumentalizados.

No podemos finalizar este trabajo sin agradecer vivamente las facilidades y las informaciones ofrecidas para su realización por Rafael Ramos, excavador e investigador del yacimiento arqueológico de llici, (La Alcudia, Elche), con quien una vez más quedamos deudores. 


\section{BIBLIOGRAFIA}

ABad CASAL, Lorenzo, 1984: Los orígenes de la ciudad de Alicante, Alicante.

ABAD, L. y ABASCAL, J.M., 1991: Textos para la Historia de Alicante. Edad Antigua, Alicante.

Aubet Semmler, $M^{3}$ Eugenia, 1982: El santuario de Es Cuieram. Ibiza, Ibiza.

Beltrán MARTínez, 1994: Elche y su bimilenario a través de las monedas, Elche.

BLÁZQUEZ MARTíneZ, José Ma, 1956: “Las Diosas sagradas de Elche (Alicante)», IV Congreso Internacional de Ciencias Prehistóricas y Protohistóricas (Madrid 1954), Zaragoza, pp. 747748.

BlÁzQUEZ MARTinez, JOSE $M^{a}$, 1977: Imagen y Mito. Estudios sobre religiones mediterráneas e ibéricas, Madrid.

BURGHOLZER, G., 1994: "Templos in antis de la península Ibérica", XIV Congreso Internacional de Arqueología Clásica La Ciudad en el Mundo Romano, 2, Tarragona, pp. 78-79.

CINTAS, P., 1976: Manuel d' Archéologie Punique, II, Paris.

CORELL, J.: et alii, 1993, "Tres inscripciones inéditas del País Valenciano", Ficheiro Epigráfico, 43, ff. $190-192$.

CUCHIN, L.A., 1990: The local magistrates of Roman Spain, Toronto.

Garcia Bellido, Antonio, 1957: El culto a Dea Caelestis en la Peninsula lbérica, Madrid.

GonzÁlez Cravioto, Enfiove, 1983: "Relaciones comerciales entre Carthago Nova y Mauritania durante el Principado de Augusto", Anales de la Universidad de Murcia, Letras, vol. XL, 34 (1981-82), pp. 13-26.

Halsberghe, G.H., 1984: "Le culte de Dea Caelestis", A.N.R.W., II, 17.4, Berlín, pp. 2.2032.223.

LE GLAY, M., 1975: «Les syncrétismes dans l'Afrique ancienne", Les syncrétismes dans les religions de l'Antiquité, Coloque de Besançon, Leiden, pp. 123-151.

LE GLAY, M, 1984, "Les religions de I Afrique romaine au II siècle d'après Apulée et les inscriptions", Atti I Convegno L'AFRICA ROMANA (Sassari 1983), Sassari, pp. 47-61.

LLORENS ForCADA, Ma DEL MAR, 1987: La ceca de llici, Valencia.

Maestro Zaldivar, Elena Ma ${ }^{\mathrm{a}}$ 1989: Cerámica ibérica decorada con figura humana, Zaragoza.

Marin Ceballos, M” Cruz, 1987: “¿ ¿Tanit en España?», Lucentum, VI, pp. 43-79.

Marín Ceballos, Ma Cruz, 1993: "Dea Caelestis en la epigrafía hispana", / Congresso Peninsular de História Antiga (Coimbra 1990), Coimbra, pp. 825-845.

Marín Ceballos, M" Cruz, 1994: "Dea Caelestis en un santuario ibérico", Coloquios de Cartagena, I. El Mundo Púnico. Historia, Sociedad y Cultura (Cartagena 1990), Murcia, pp. 217-225.

MENÉNDEZ, M., 1988: La cerámica de estilo Elche-Archena, Tesis Doctoral, Universidad Complutense, Madrid.

Molina, J. y POVEDA, A.M., en prensa, "El nivel de abandono de un sector del foro de llici", XXIII Congreso Nacional de Arqueología (Elche 1995).

MORENA LóPEZ, José A., 1989: El santuario ibérico de Torreparedones (Castro del Río-Baena, Córdoba), Córdoba.

NoRdSTRÖM, SolveIG, 1973: La cerámique peinte ibérique de la province d'Alicante, Estocolmo.

Picard, G. Charles, 1954: Les religions de l'Afrique Antique, Paris.

Poveda Navarro, ANTONIO M., 1995: “Un nuevo conjunto escultórico ibérico del sudeste: los hallazgos de "El Monastil» (Elda, Alicante)", XXII Congreso Nacional de Arqueología (Vigo. 1993), Vigo.

Rabanal Alonso, Manuel A., 1985: "La ciudad de Alicante en las fuentes literarias y epigráficas antiguas". Studia Historica in honorem Vicente Martinez Morellá, Alicante, pp. 375-384.

Rabanal Alonso, Manuel A. y ABAsCal, J.M., 1985: "Inscripciones romanas de la provincia de Alicante", Lucentum, 4, pp. 191-244.

Ramos Fernández, Rafael, 1988: "Simbolismo de la esfinge de Elche", Archivo de Prehistoria Levantina. XVIII, pp. 367-385.

Ramos Fernández, Rafael, 1975: La ciudad romana de llici, Alicante.

Ramos Fernández, RAFAel, 1991: Simbología de la cerámica ibérica de la Alcudia de Elche, Elche.

Ramos Fernandez, Rafael, 1994: El Elche de hace 2000 años, Elche.

RAMOS FERnÁNDEZ, RAFAEL, 1995a, "Un templo romano de época augustea en la Alcudia de Elche", XXII Congreso Nacional de Arqueología (Vigo 1993), II, Vigo, pp. 349-353. 
Ramos Fernández, Rafael, 1995b, El templo ibérico de La Alcudia. La Dama de Elche, Elche. Ramos Foloués, Alejandro, 1990: Cerámica ibérica de La Alcudia (Elche-Alicante), Alicante.

TAFALLA, D., 1972: El Lucentum hispano-romano de Benalúa-Antigons, siglo // d.C., Historia de Alicante y castillo, Alicante.

VÁzOUEZ HOYS, ANA $\mathrm{M}^{a}$, en prensa, “A propósito de la serpiente en las cerámicas ibéricas de Elche", XXIII Congreso Nacional de Arqueología (Elche, 1995$).$

VIVES y ESCUdERO, ANTONIO, 1926: La moneda hispánica, Madrid. 